\title{
Influência do uso e ocupação do solo nos recursos hídricos do Córrego Três Barras, Marinópolis ${ }^{1}$
}

\author{
$\overline{\text { Luiz. S. Vanzela }{ }^{2} \text {, Fernando B. T. Hernandez }{ }^{3} \& \text { Renato A. M. Franco }{ }^{4}}$
}

\begin{abstract}
RESUMO
O uso e a ocupação dos solos exercem influência marcante no escoamento superficial e aporte de sedimentos no leito dos mananciais, podendo alterar a qualidade e a disponibilidade da água. Com isto se objetivou com o presente trabaIho, verificar a influência do uso e ocupação dos solos sobre os recursos hídricos do córrego Três Barras, município de Marinópolis, SP. Para constatar esta influência, realizou-se uma análise de correlação de Pearson entre os parâmetros de qualidade e disponibilidade de água e o uso e ocupação dos solos, cujos dados foram coletados entre 18/01/2006 a 10/12/2007. Concluiu-se que as áreas ocupadas por matas e pastagens (com menor intensidade) favoreceram a disponibilidade e a qualidade da água na Sub-Bacia. De maneira geral, as áreas habitadas, agricultadas e as matas degradadas, reduziram a disponibilidade e a qualidade da água da Sub-Bacia.
\end{abstract}

Palavras-chave: correlação estatística, qualidade de água, aporte de sedimentos

\section{Influence of land use and occupation on water resources of the Três Barras stream (Marinópolis, SP, Brazil)}

\begin{abstract}
Land occupation and its use have a remarkable influence on the superficial water flow and the carrying of sediments to the riverbed and may change the quality and availability of water. The current study aimed to check the influence of the land occupation and use on the Três Barras stream resources, in Marinópolis, SP, Brazil. To check this influence, an analysis of Pearson's correlation between the parameters of quality and availability and use of water and land was developed. The samples covered the period of January, 2006 until December, 2007. It may be concluded that areas occupied by forests and pastures (in less intensity) favoured the availability and quality of water of the watershed. The inhabited areas and those used for agriculture, and the degraded forests in general, reduced the availability and quality of water in the watershed.
\end{abstract}

Key words: statistical correlation, water quality, silting

\footnotetext{
1 Financiamento FAPESP/FEHIDRO Empreendimento SJD - 133

2 UNICASTELO, CEP 15600-000, Fernandópolis, SP. Fone: (17) 3465-4200. E-mail: Isvanzela@yahoo.com.br

3 UNESP, CP 34, CEP 15385-000, Ilha Solteira, SP. Fone: (18) 3743-1180. E-mail: fbthtang@agr.feis.unesp.br

${ }^{4}$ Doutorando em Agronomia/UNESP. Fone: (18) 3742-4008. E-mail: bioramfranco@yahoo.com.br
} 


\section{INTRODUÇÃO}

O desenvolvimento econômico agrícola do Brasil tem sido, nas últimas décadas, tem sido caracterizado pelo uso intensivo dos recursos naturais sem o devido planejamento o que, aliado às características de solo e clima, promoveu grandes perdas de solo por erosão. Ressalta-se que só no Estado de São Paulo 83\% dos municípios são considerados de média a alta criticidade a erosão (São Paulo, 2006). Este evento se deve ao fato da maioria dos solos ser constituída de Argissolos (Oliveira et al., 1999) que, além de possuírem alta erodibilidade, estão associadas às precárias condições de conservação do solo. Outro agravante é a baixa cobertura de vegetação nativa ainda preservada (13,9\% do Estado e apenas 2,3\% na área da Bacia Hidrográfica do Rio São José dos Dourados - BH-SJD, onde se insere este trabalho) e ainda a baixa disponibilidade hídrica específica (vazão média específica de 27,28 $\mathrm{m}^{3} \mathrm{~h}^{-1} \mathrm{~km}^{-2}$ e $\mathrm{Q}_{7,10}$ específica de $6,47 \mathrm{~m}^{3} \mathrm{~h}^{-1} \mathrm{~km}^{-2}$ na BH-SJD) conforme São Paulo (2006).

As consequências desses fatores são o carreamento de grandes quantidades de solo, matéria orgânica e insumos agrícolas para o leito dos cursos d’água no período chuvoso, contribuindo significativamente com o aumento da concentração de sólidos e nutrientes na água dos mananciais. Outro tipo de contaminante que pode ser transportado para o leito do manancial são os coliformes, como já observado por Gonçalves et al. (2005).

A principal consequência deste impacto é o assoreamento que, além de modificar ou deteriorar a qualidade da água, a fauna e a flora, provoca o decréscimo da velocidade da água resultando também na redução da disponibilidade hídrica. Andrade et al. (2007), com o objetivo de identificar os fatores determinantes (naturais e antrópicos) da qualidade das águas superficiais da Bacia Hidrográfica do Alto Acaraú, concluíram que os parâmetros indicadores da qualidade das águas estão relacionados principalmente com a solubilidade dos sais (ação natural), com nutrientes e transporte de sedimentos (ação antrópica), sendo o principal fator a geologia da região.

Os fatores que influenciam o aporte de sedimentos em bacias hidrográficas são relevos, tipos de solos, climas e usos e ocupação dos solos; dentre esses fatores a cobertura do solo tem influência decisiva nas perdas de água e solo (Silva et al., 2005), podendo influenciar indiretamente na disponibilidade e na qualidade da água, se considerados os condicionantes anteriormente citados.

De acordo com Silva et al. (2005), o efeito da cobertura do solo sobre as perdas de água e solo, pode ser explicado pela ação que a cobertura do solo tem em dissipar a energia cinética do impacto direto das gotas da chuva sobre a superfície, diminuindo a desagregação inicial das partículas de solo e, consequentemente, a concentração de sedimentos na enxurrada; além disso, a cobertura do solo representa um obstáculo mecânico ao livre escoamento superficial da água, ocasionando diminuição da velocidade e da capacidade de desagregação e transporte de sedimentos. Donadio et al. (2005), avaliando a influência da vegetação natural remanescente e de atividades agrícolas na qualidade da água de quatro nascentes, concluíram que os períodos de amostragem, assim como as características do solo e seus diferentes usos, influenciam na qualidade da água das sub-bacias.

No mundo globalizado e de alta competição, torna-se necessário que a agricultura seja praticada de forma intensiva e com alta produtividade. Logo, é imprescindível a adoção da tecnologia da irrigação, pois ela possibilita alta produção, padronização e qualidade dos produtos e, principalmente, a produção em períodos fora de época, quando os preços pagos ao produtor são maiores (Hernandez et al., 2003). Considerando que a irrigação é uma prática que consome grandes volumes de água, a oferta de água pelos mananciais deve ser preservada e ampliada sendo a cobertura do solo um fator decisivo no escoamento superficial e no transporte de sedimentos, podendo influenciar indiretamente a qualidade e disponibilidade de água dos mananciais. O estabelecimento de correlações entre o uso e a ocupação dos solos e os recursos hídricos, é uma importante informação para o planejamento dos recursos hídricos na bacia hidrográfica.

Sendo assim, o presente trabalho teve como objetivo verificar a influência do uso e ocupação dos solos sobre os recursos hídricos do Córrego Três Barras, município de Marinópolis, SP.

\section{MATERIAL E MÉTODOS}

Este trabalho foi conduzido na Sub-Bacia Hidrográfica do córrego Três Barras, localizada no perímetro rural do município de Marinópolis, SP, nos domínios da Bacia Hidrográfica do Rio São José dos Dourados, entre as coordenadas geográficas de $20^{\circ} 24$ ' 49" Sul e $50^{\circ} 0$ ' $00^{\prime}$ " Oeste e $20^{\circ} 28^{\prime} 52^{\prime \prime}$ Sul e $50^{\circ} 47^{\prime}$ 33” Oeste (Figura 1).

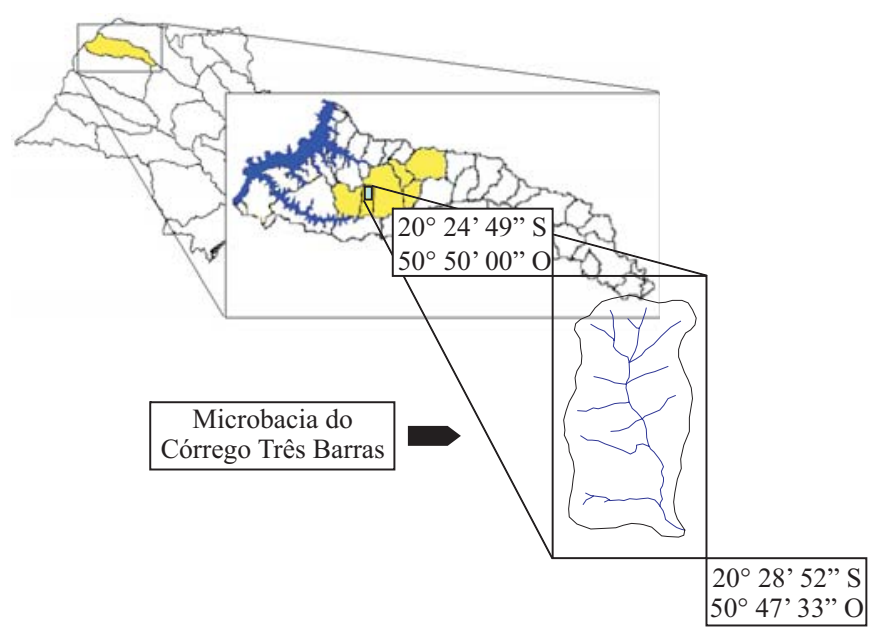

Figura 1. Localização da Sub-Bacia do córrego Três Barras

De acordo com o CBH-SJD (2000), as unidades geológicas que afloram nesta bacia são as rochas ígneas basálticas do Grupo São Bento, Formação Serra Geral, e as rochas sedimentares do Grupo Bauru, Formação Caiuá. Segundo Oliveira et al. (1999) os solos da sub-bacia são classificados como Argissolos Vermelhos Escuros. O clima da região segundo Koppen é classificado como tropical, Aw, 
com inverno seco e ameno e verão quente e chuvoso (Rolim et al., 2007), com temperatura média anual de $24,1^{\circ} \mathrm{C}$ e precipitação média anual de $1.166 \mathrm{~mm}$.

A base cartográfica utilizada para a delimitação da subbacia foi o mapa planialtimétrico em escala de 1:10.000 elaborado por fotogrametria em 2001, pela equipe de engenharia da Coordenadoria de Assistência Técnica Integral CATI Regional Jales. As características fisiográficas e quantitativas dos recursos hídricos estão apresentadas na Tabela 1.

Tabela 1. Características fisiográficas e aspectos quantitativos dos recursos hídricos da Sub-Bacia do Córrego Três Barras, Marinópolis, SP

\begin{tabular}{lc}
\hline Característica & Valor \\
Área de drenagem & $17,77 \mathrm{~km}^{2}$ \\
Perímetro & $20,04 \mathrm{~km}$ \\
Comprimento leito principal & $6,61 \mathrm{~km}$ \\
Elevação média & $393 \mathrm{~m}$ \\
Declividade equivalente & $0,009 \mathrm{~m} \mathrm{~m}^{-1}$ \\
Fator de forma & 1,34 \\
Coeficiente de compacidade & 1,33 \\
Densidade de drenagem & $2,1 \mathrm{~km} \mathrm{~km}^{-2}$ \\
Ordem & $3 \mathrm{a}$ \\
Tempo de concentração & $105 \mathrm{~min}^{-13}$ \\
Vazão média plurianual & $414,0 \mathrm{~m}^{3} \mathrm{~h}^{-1}$ \\
Vazão de permanência com 95\% de probabilidade & $129,6 \mathrm{~m}^{3} \mathrm{~h}^{-1}$ \\
Vazão mínima de 1 mês consecutivo com período de & $118,8 \mathrm{~m}^{3} \mathrm{~h}^{-1}$ \\
retorno de 10 anos & \\
Vazão mínima de 7 dias consecutivos com período de & $97,2 \mathrm{~m}^{3} \mathrm{~h}^{-1}$ \\
retorno de 10 anos &
\end{tabular}

A análise estatística consistiu na análise exploratória dos atributos hídricos e na análise de correção entre o uso e ocupação do solo e os parâmetros hídricos; para isto, a Sub-Bacia hidrográfica foi dividida em 5 sub-bacias, definidas por pontos de medições de vazão e amostragem da água (Figura 2). Os locais de coleta dos dados de qualidade da água e da vazão foram definidos de acordo com os seguintes critérios: (1) influência das características locais sobre a qualidade da água; (2) subdivisão da sub-bacia em pontos equidistantes; desta forma, cada ponto monitorado permitiu a delimitação, de acordo com o divisor de águas, as sub-bacias 1, 2, 3, 4 e 5 (SB 1, SB 2, SB 3, SB 4 e SB 5), cujas características estão apresentadas na Tabela 2.

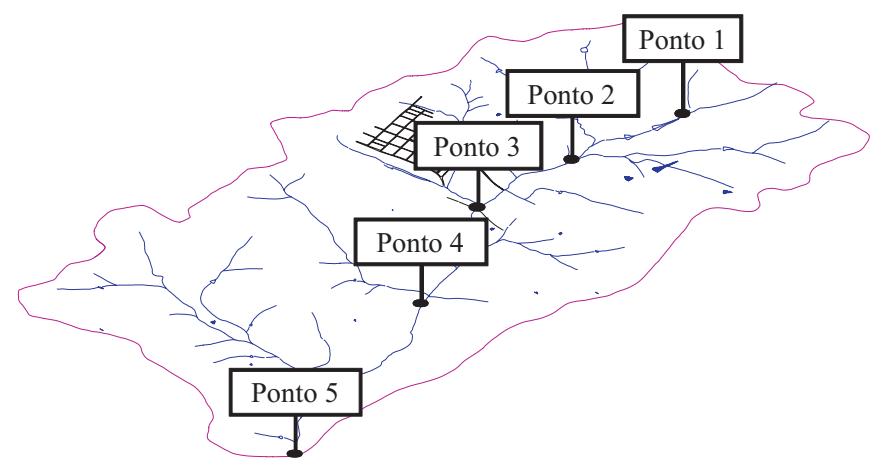

$\overline{\text { Figura 2. Localização dos pontos de medição de vazões e amostragem }}$ de água
Tabela 2. Características das sub-bacias avaliadas

\begin{tabular}{|c|c|c|c|c|c|}
\hline Característica & SB 1 & SB 2 & SB 3 & SB 4 & SB 5 \\
\hline $\begin{array}{l}\text { Área de drenagem } \\
\left(\mathrm{km}^{2}\right)\end{array}$ & 0,70 & 4,65 & 6,87 & 13,16 & 17,77 \\
\hline Perímetro $(\mathrm{km})$ & 3,40 & 9,45 & 11,30 & 16,50 & 20,04 \\
\hline $\begin{array}{l}\text { Comprimento do leito } \\
\text { Principal }(\mathrm{km})\end{array}$ & 0,815 & 1,960 & 2,823 & 5,376 & 6,610 \\
\hline Elevação média (m) & 409 & 402 & 399 & 395 & 393 \\
\hline $\begin{array}{l}\text { Declividade Equivalente } \\
\left(\mathrm{m} \mathrm{m}^{-1}\right)\end{array}$ & 0,019 & 0,019 & 0,013 & 0,007 & 0,009 \\
\hline Fator de forma & 1,15 & 1,21 & 1,22 & 1,28 & 1,34 \\
\hline $\begin{array}{l}\text { Coeficiente de } \\
\text { compacidade }\end{array}$ & 1,14 & 1,23 & 1,21 & 1,27 & 1,33 \\
\hline $\begin{array}{l}\text { Densidade de } \\
\text { drenagem }\left(\mathrm{km} \mathrm{km}^{-1}\right)\end{array}$ & 1,97 & 2,12 & 2,27 & 2,08 & 2,1 \\
\hline
\end{tabular}

Os atributos hídricos analisados foram: vazão específica $\left(\mathrm{Q}_{\mathrm{esp}}\right)$, descarga sólida total específica (DST $\left.\mathrm{esp}_{\mathrm{e}}\right)$, temperatura da água (T), turbidez (TD), sólidos suspensos (SS), sólidos dissolvidos (SD), sólidos totais (ST), coliformes fecais (CF), coliformes totais (CT), potencial hidrogeniônico $(\mathrm{pH})$, condutividade elétrica (CE), ferro total (Fe), oxigênio dissolvido (OD), cálcio (Ca), magnésio (Mg) e dureza total (DT).

As vazões foram medidas pelo método do molinete hidrométrico modelo FP101-FP201 (Global Flow Probe), em que as velocidades do fluxo são obtidas em uma seção (no caso de seções inferiores a $0,50 \mathrm{~m}$ ) ou em diversas seções molhadas ao longo da largura do curso d’água; a descarga sólida total foi determinada pelo método de Colby (1957) (Carvalho, 1994).

As coletas das amostras de água para análise e medições de vazões, foram realizadas em intervalos aproximados de 30 dias, no período de 18/01/2006 a 10/12/2007, totalizando 24 amostragens de água para determinação dos parâmetros avaliados e medição de vazões de descargas sólidas, as quais corresponderam às repetições.

As metodologias utilizadas na determinação dos atributos de qualidade de água e as precisões de cada método estão apresentadas na Tabela 3 .

A determinação das classes de uso e ocupação do solo foi realizada sobre a ortofoto digital no formato "GEOTIFF”, obtida por fotogrametria e cedida pela equipe de engenharia da CATI - Regional Jales; para isto, a ortofoto foi importada para o software Spring 4.3.3, a partir do qual se realizou

Tabela 3. Síntese das metodologias e dos equipamentos empregados nas análises dos atributos de qualidade de água avaliados

\begin{tabular}{llc}
\hline \multicolumn{1}{c}{ Parâmetros } & \multicolumn{1}{c}{ Método } & Precisão \\
Temperatura & Termômetro & $0,5{ }^{\circ} \mathrm{C}$ \\
$\begin{array}{l}\text { Sólidos suspensos, } \\
\text { dissolvidos e totais }\end{array}$ & Gravimétrico & $1,0 \mathrm{mg} \mathrm{L}^{-1}$ \\
Turbidez & Nefelométrico & $0,1 \mathrm{NTU}$ \\
$\mathrm{pH}$ & Peagâmetro & 0,01 \\
Condutividade elétrica & Eletrodo de platina & $0,1 \mu \mathrm{cm}^{-1} \mathrm{a} 25^{\circ} \mathrm{C}$ \\
Ferro total & Colorimétrico ferroespectral & $0,1 \mathrm{mg} \mathrm{L}^{-1}$ \\
Oxigênio dissolvido & Winkler modificado & $0,1 \mathrm{mg} \mathrm{L}^{-1}$ \\
Cálcio, magnésio e dureza \\
total & Titulação & $1,0 \mathrm{mg} \mathrm{L}^{-1}$ \\
Coliformes fecais e & Contagem de bactérias & $60 \mathrm{NMP}^{*} 100 \mathrm{~mL}^{-1}$ \\
Coliformes totais & &
\end{tabular}

R. Bras. Eng. Agríc. Ambiental, v.14, n.1, p.55-64, 2010. 
Tabela 4. Uso e ocupação dos solos para as Sub-Bacias avaliadas

\begin{tabular}{|c|c|c|c|c|c|}
\hline \multirow{2}{*}{ Uso e Ocupação } & SB 1 & SB 2 & SB 3 & SB 4 & SB 5 \\
\hline & \multicolumn{5}{|c|}{$\%$} \\
\hline Pastagem (P) & 64,42 & 52,78 & 47,09 & 52,24 & 53,90 \\
\hline Culturas perenes (CP) & 8,82 & 24,34 & 29,82 & 26,87 & 26,81 \\
\hline $\begin{array}{l}\text { Vegetação de várzeas } \\
\text { (W) }\end{array}$ & 8,09 & 6,62 & 6,58 & 7,59 & 7,33 \\
\hline Matas (M) & 10,44 & 3,28 & 3,00 & 2,13 & 3,04 \\
\hline Área urbana (AU) & 0,00 & 0,00 & 2,16 & 3,19 & 2,36 \\
\hline $\begin{array}{l}\text { Culturas perenes } \\
\text { irrigadas (CPI) - Videiras }\end{array}$ & 0,00 & 4,50 & 3,33 & 2,10 & 1,56 \\
\hline Matas degradadas (MD) & 1,60 & 2,01 & 2,09 & 1,52 & 1,37 \\
\hline $\begin{array}{l}\text { Faixa da rodovia } \\
\text { pavimentada (FRP) }\end{array}$ & 3,91 & 1,90 & 1,63 & 1,34 & 1,05 \\
\hline Moradias rurais (MR) & 0,00 & 1,44 & 1,56 & 1,15 & 1,04 \\
\hline Estradas rurais (ER) & 2,73 & 2,51 & 2,32 & 1,65 & 1,38 \\
\hline Culturas anuais (CA) & 0,00 & 0,62 & 0,42 & 0,22 & 0,16 \\
\hline
\end{tabular}

a delimitação das classes de uso e ocupação do solo por digitalização manual na edição vetorial, na medida em que as classes foram sendo identificadas pelo processo de interpretação visual. A atualização das classes de uso e ocupação foram sendo realizadas na ocasião das visitas de campo aos pontos de monitoramento hídrico.

As classes de uso e ocupação delimitadas foram: pastagem (P), culturas perenes (CP), vegetação de várzeas (VV), matas (M), área urbana (AU), culturas perenes irrigadas (CPI) representadas pelas videiras, matas degradadas (MD), faixas laterais das rodovias pavimentadas (FRP), moradias rurais (MR), estradas rurais (ER) e culturas anuais (CA). Na Tabela 4 se encontram as proporções de cada uso e ocupação para cada Sub-Bacia avaliada.

A análise exploratória dos resultados foi constituída da média seguida do erro padrão da média e dos valores máximos e mínimos. Realizou-se a análise de correlação utilizando-se o coeficiente de correlação de Pearson, com análise de variância a nível de $5 \%\left(^{*}\right)$ e $1 \%(* *)$ de probabilidade, em que as variáveis dependentes foram os atributos hídricos e as variáveis independentes, o uso e ocupação dos solos.

As correlações significativas ainda foram submetidas a classificação de Hopkins (2008), que estabelece classes para o Coeficiente de Correlação: $0,0<\mathrm{r} \leq 0,1$ (Muito baixa), 0,1<r $\leq 0,3$ (Baixa) 0,3<r $\leq 0,5$ (Moderada), $0,5<\mathrm{r} \leq 0,7$ (Alta), 0,7 $<\mathrm{r} \leq 0,9$ (Muito alta) e $0,9<\mathrm{r} \leq 1,0$ (Extremamente Alta). Após a classificação se confeccionaram os mapas de correlação visando identificar espacialmente as áreas correlacionadas com os parâmetros hídricos avaliados; posteriormente, para as correlações de maior interesse também se realizaram análises de regressão a nível de 5\% de probabilidade; todas as análises estatísticas foram feitas com o auxílio do software SPSS 11.0 e os mapas de correlação, confeccionados com o auxílio do software Arcview 3.2.

\section{RESULTADOS E DISCUSSÃO}

Apresentam-se, nas Tabelas 5 e 6, as análises exploratórias iniciais dos atributos dos recursos hídricos ao longo do córrego Três Barras, Marinópolis, SP e na Tabela 7, o resultado da análise de correlação entre os atributos hídricos avaliados e o uso e ocupação dos solos da Sub-Bacia do Córrego Três Barras.

De acordo com os resultados, observa-se, com exceção dos atributos descarga sólida total específica, temperatura da água e sua turbidez, que os demais atributos apresentaram correlação significativa com pelo menos cinco tipos diferentes de uso e ocupação dos solos. Em função da correlação positiva verificou-se que a vazão específica foi influenciada significativamente pelas áreas de matas, faixas de rodovias pavimentadas e pelas pastagens (correlação baixa). A correlação positiva com as faixas de rodovias pavimentadas se deve, provavelmente, ao fato dessas áreas serem ocupadas por vegetação similar a um campo sujo (forrageiras e outros tipos de vegetação) associadas à presença de bacias de captação de água (Figura 3A).

As áreas de matas são áreas mais cobertas e estáveis, com maior capacidade de infiltração e armazenamento de água no solo aumentando, assim, o tempo de caminhamento da água ao leito do manancial. Com isto, as áreas com essas ocupações tendem a reduzir o escoamento superficial, efeito este já evidenciado por Silva et al. (2005), ao verificarem que a cobertura completa do solo evita a desagregação provocada pelo impacto das gotas de chuva e a formação do selamento superficial favorecendo, consequentemente, a infiltração da água no solo e a redução do escoamento superficial. As pastagens apresentaram menor correlação positiva, visto que, embora bem manejadas e proporcionem boa cobertura do solo, se caracterizam por menores valores de infiltração de água no solo, condutividade hidráulica e maior valor de resistência do solo à penetração, em relação à vegetação natural (Zigomar \& Alves, 2003).

As áreas habitadas (área urbana e moradias rurais) e as áreas de culturas perenes tenderam a reduzir a vazão específica. Essas ocupações são caracterizadas pela redução da permeabilidade do solo, seja pela impermeabilização e/ou compactação no caso das áreas habitadas ou pela alteração das propriedades físicas, como a compactação nas áreas agricultadas. Segundo Gomes et al. (2007) é de se esperar que a dinâmica de uso e ocupação do solo afete a variabilidade de alguns atributos físicos do solo principalmente daqueles que herdam influência do manejo, caso da densidade e matéria orgânica; nessas áreas a alteração dos atributos físicos é caracterizada, sobretudo pela redução da capacidade de infiltração e armazenamento de água promovendo o aumento do escoamento superficial e reduzindo a contribuição para o escoamento subterrâneo, fator importante na disponibilidade de água na época seca.

Com relação à qualidade de água, notou-se que, de maneira geral, o aumento da concentração dos sólidos na água do manancial tem origem nas áreas agricultadas (culturas perenes, culturas perenes irrigadas e culturas anuais), nas áreas habitadas (área urbana e moradias rurais) e nas matas degradadas (Figura 3B, C e D), em função das correlações positivas verificadas. Esses resultados concordam com os obtidos por Toledo \& Niconella (2002) que, avaliando o índice de qualidade de água em microbacia sob diferentes usos, 
Tabela 5. Análise exploratória dos atributos físicos de qualidade de água, vazão específica e descarga sólida específica

\begin{tabular}{|c|c|c|c|c|c|c|}
\hline Parâmetro & Resultado & SB 1 & SB 2 & SB 3 & SB 4 & SB 5 \\
\hline \multirow{3}{*}{$Q_{e s p}\left(m^{3} h^{-1} k^{-2}\right)$} & Méd. \pm EPM & $51,51 \pm 12,76$ & - & $34,00 \pm 6,20$ & $21,62 \pm 3,35$ & $19,31 \pm 2,07$ \\
\hline & Máx. & 230,6 & - & 131,8 & 71,3 & 42,2 \\
\hline & Mín. & 5,8 & - & 1,7 & 2,1 & 2,5 \\
\hline \multirow[t]{3}{*}{$\mathrm{DST}_{\text {esp }}\left(\mathrm{t} \mathrm{km}^{-2} \mathrm{~d}^{-1}\right)$} & Méd. \pm EPM & $0,292 \pm 0,087$ & - & $0,256 \pm 0,054$ & $0,228 \pm 0,041$ & $0,118 \pm 0,014$ \\
\hline & Máx. & 1,515 & - & 1,187 & 0,885 & 0,257 \\
\hline & Mín. & 0,026 & - & 0,011 & 0,017 & 0,019 \\
\hline \multirow[t]{3}{*}{$\mathrm{T}\left({ }^{\circ} \mathrm{C}\right)$} & Méd. \pm EPM & $23,3 \pm 0,7$ & $23,5 \pm 0,8$ & $22,8 \pm 0,7$ & $24,9 \pm 0,8$ & $23,9 \pm 0,9$ \\
\hline & Máx. & 28,0 & 28,0 & 27,0 & 30,0 & 29,5 \\
\hline & Mín. & 19,0 & 19,0 & 18,0 & 19,0 & 18,0 \\
\hline \multirow[t]{3}{*}{ TD (NTU) } & Méd. \pm EPM & $11,4 \pm 2,2$ & $7,1 \pm 1,1$ & $16,3 \pm 2,9$ & $13,9 \pm 2,2$ & $13,1 \pm 1,7$ \\
\hline & Máx. & 36,0 & 18,0 & 45,0 & 34,7 & 26,0 \\
\hline & Mín. & 1,7 & 0,0 & 1,6 & 1,5 & 3,1 \\
\hline \multirow{3}{*}{ SS $\left(\mathrm{mg} \mathrm{L}^{-1}\right)$} & Méd. \pm EPM & $21,4 \pm 6$ & $33,3 \pm 6,1$ & $43,6 \pm 5,2$ & $26,4 \pm 6,8$ & $38,8 \pm 6,7$ \\
\hline & Máx. & 112,0 & 95,0 & 78,0 & 73,0 & 126,0 \\
\hline & Mín. & 3,0 & 5,0 & 11,0 & 0,0 & 7,0 \\
\hline \multirow[t]{3}{*}{$\mathrm{SD}\left(\mathrm{mg} \mathrm{L}^{-1}\right)$} & Méd. \pm EPM & $94,2 \pm 10$ & $110,1 \pm 7,4$ & $163,4 \pm 17,5$ & $144,2 \pm 9,6$ & $119,1 \pm 8$ \\
\hline & Máx. & 153,0 & 176,0 & 281,0 & 194,0 & 158,0 \\
\hline & Mín. & 2,0 & 61,0 & 45,0 & 76,0 & 1,0 \\
\hline \multirow[t]{3}{*}{ ST $\left(\mathrm{mg} \mathrm{L}^{-1}\right)$} & Méd. \pm EPM & $115,6 \pm 7,3$ & $143,3 \pm 6,6$ & $207,0 \pm 19,9$ & $170,6 \pm 9,9$ & $157,9 \pm 4,1$ \\
\hline & Máx. & 167,0 & 188,0 & 359,0 & 255,0 & 201,0 \\
\hline & Mín. & 59,0 & 98,0 & 77,0 & 83,0 & 127,0 \\
\hline
\end{tabular}

OBS: Méd. (média); EPM (erro padrão da média), Máx. (valor máximo), Mín. (valor mínimo), Qesp (vazão específica), DSTesp (descarga sólida específica), T (temperatura a água), TD (turbidez), SS (sólidos suspensos), SD (sólidos dissolvidos), ST (sólidos totais)

Tabela 6. Análise exploratória dos atributos químicos e biológicos de qualidade de água

\begin{tabular}{|c|c|c|c|c|c|c|}
\hline Parâmetro & Resultado & SB 1 & SB 2 & SB 3 & SB 4 & SB 5 \\
\hline \multirow[t]{3}{*}{$\mathrm{pH}$} & Méd. I EPM & $7,31 \pm 0,06$ & $7,08 \pm 0,05$ & $6,98 \pm 0,06$ & $7,26 \pm 0,07$ & $7,46 \pm 0,04$ \\
\hline & Máx. & 7,8 & 7,5 & 7,5 & 7,8 & 7,8 \\
\hline & Mín. & 6,9 & 6,6 & 6,6 & 6,8 & 7,1 \\
\hline \multirow[t]{3}{*}{$\mathrm{CE}\left(\mu \mathrm{S} \mathrm{cm}^{-1}\right)$} & Méd. \pm EPM & $174,7 \pm 16,6$ & $200,3 \pm 6,5$ & $351,5 \pm 25,6$ & $263,7 \pm 11,6$ & $211,4 \pm 11,5$ \\
\hline & Máx. & 399,0 & 286,0 & 590,0 & 356,0 & 279,0 \\
\hline & Mín. & 63,0 & 151,9 & 155,2 & 178,0 & 52,0 \\
\hline \multirow[t]{3}{*}{ Fe $\left(m g L^{-1}\right)$} & Méd. \pm EPM & $0,74 \pm 0,12$ & $0,63 \pm 0,11$ & $1,54 \pm 0,29$ & $0,76 \pm 0,16$ & $0,85 \pm 0,17$ \\
\hline & Máx. & 2,00 & 2,00 & 3,00 & 2,50 & 3,00 \\
\hline & Mín. & 0,30 & 0,10 & 0,20 & 0,10 & 0,20 \\
\hline \multirow[t]{3}{*}{$\mathrm{Ca}\left(\mathrm{mg} \mathrm{L}^{-1} \mathrm{CaCO}_{3}\right)$} & Méd. \pm EPM & $58,2 \pm 3,8$ & $73,3 \pm 3,5$ & $82,7 \pm 4,8$ & $79,6 \pm 4,8$ & $74,0 \pm 3,8$ \\
\hline & Máx. & 78,0 & 90,0 & 124,0 & 108,0 & 94,0 \\
\hline & Mín. & 24,0 & 34,0 & 40,0 & 30,0 & 32,0 \\
\hline \multirow[t]{3}{*}{$\mathrm{Mg}\left(\mathrm{mg} \mathrm{L}^{-1} \mathrm{CaCO}_{3}\right)$} & Méd. \pm EPM & $38,5 \pm 3,9$ & $48,7 \pm 4,6$ & $60,2 \pm 4,9$ & $54,8 \pm 6,1$ & $50,6 \pm 4,3$ \\
\hline & Máx. & 86,0 & 98,0 & 124,0 & 122,0 & 104,0 \\
\hline & Mín. & 8,0 & 30,0 & 26,0 & 24,0 & 34,0 \\
\hline \multirow[t]{3}{*}{ DT $\left(\mathrm{mg} \mathrm{L}^{-1} \mathrm{CaCO}_{3}\right)$} & Méd. \pm EPM & $96,7 \pm 4,4$ & $122,0 \pm 4,9$ & $142,9 \pm 4,8$ & $134,4 \pm 5,1$ & $124,6 \pm 5,1$ \\
\hline & Máx. & 124,0 & 168,0 & 172,0 & 170,0 & 170,0 \\
\hline & Mín. & 44,0 & 82,0 & 104,0 & 98,0 & 80,0 \\
\hline \multirow[t]{3}{*}{ OD (mg L-1) } & Méd. \pm EPM & $8,0 \pm 1,0$ & $3,9 \pm 0,7$ & $5,3 \pm 0,6$ & $7,1 \pm 0,7$ & $8,1 \pm 0,9$ \\
\hline & Máx. & 15,4 & 12,2 & 10,2 & 12,8 & 15,6 \\
\hline & Mín. & 2,2 & 1,0 & 1,8 & 3,2 & 2,4 \\
\hline \multirow[t]{3}{*}{ CF (NMP 100mL-1) } & Méd. \pm EPM & $78 \pm 42$ & $110 \pm 55$ & $14958 \pm 2857$ & $651 \pm 394$ & $344 \pm 174$ \\
\hline & Máx. & 660 & 900 & 48000 & 6400 & 3200 \\
\hline & Mín. & 0 & 0 & 1800 & 0 & 0 \\
\hline \multirow[t]{3}{*}{ CT (NMP 100mL-1) } & Méd. \pm EPM & $946 \pm 280$ & $801 \pm 241$ & $65654 \pm 11237$ & $1941 \pm 1035$ & $1580 \pm 722$ \\
\hline & Máx. & 4200 & 4320 & 189000 & 17280 & 13440 \\
\hline & Mín. & 0 & 60 & 9000 & 60 & 180 \\
\hline
\end{tabular}

OBS: Méd. (média); EPM (erro padrão da média), Máx. (valor máximo), Mín. (valor mínimo),pH (potencial hidrogeniônico), CE (condutividade elétrica), Fe (ferro total), OD (oxigênio dissolvido), Ca (cálcio), Mg (magnésio), DT (dureza total), CF (coliformes fecais) e CT (coliformes totais)

verificaram influências das áreas agricultadas e urbanas na contribuição com sedimentos.

As áreas agricultadas sem o devido manejo conservacionista, se tornam grandes fontes potenciais de sedimentos fato este já observado por Gomes et al. (2007) em lavoura de milho localizada na área de recarga de duas nascentes; além disso, Bertol et al. (2004), afirmaram que o preparo convencional do solo por arações e gradagens é caracterizado pela 
Tabela 7. Análise de correlação entre os atributos hídricos e o uso e ocupação do solo

\begin{tabular}{|c|c|c|c|c|c|c|c|c|c|c|c|}
\hline \multirow{2}{*}{ Atributos hídricos } & \multicolumn{11}{|c|}{ Uso e ocupação } \\
\hline & $\mathbf{P}$ & $\mathrm{CP}$ & VV & M & AU & CPI & MD & FRP & MR & ER & CA \\
\hline$Q_{e s p}\left(m^{3} h^{-1} \mathrm{~km}^{-2}\right)$ & $0,226^{*}$ & $-0,287$ ** & 0,150 & $0,311 * *$ & $-0,322^{\star *}$ & $-0,180$ & 0,120 & $0,332^{* *}$ & $-0,242^{*}$ & 0,010 & $-0,140$ \\
\hline $\mathrm{DST}_{\text {esp }}\left(\mathrm{t} \mathrm{km}^{-2} \mathrm{~d}^{-1}\right)$ & 0,060 & $-0,110$ & 0,040 & 0,120 & $-0,110$ & $-0,020$ & 0,140 & 0,160 & $-0,070$ & 0,100 & 0,000 \\
\hline $\mathrm{T}\left({ }^{\circ} \mathrm{C}\right)$ & 0,020 & 0,020 & 0,060 & $-0,050$ & 0,070 & $-0,020$ & $-0,110$ & $-0,060$ & $-0,010$ & $-0,050$ & $-0,030$ \\
\hline TD (NTU) & $-0,149$ & 0,125 & $-0,077$ & $-0,084$ & 0,138 & 0,036 & 0,076 & $-0,081$ & 0,102 & 0,001 & 0,019 \\
\hline SS (mg L-1) & $-0,239 * *$ & 0,211 * & $-0,219^{*}$ & $-0,179$ & 0,098 & $0,187^{*}$ & $0,168^{*}$ & $-0,158$ & $0,225^{*}$ & 0,141 & 0,173 \\
\hline $\mathrm{SD}\left(\mathrm{mg} \mathrm{L}^{-1}\right)$ & $-0,367 * *$ & 0,328 ** & $-0,228^{*}$ & $-0,256 * *$ & $0,297 * *$ & 0,153 & 0,170 & $-0,244^{* *}$ & $0,289 * *$ & 0,060 & 0,120 \\
\hline $\mathrm{ST}\left(\mathrm{mg} \mathrm{L}^{-1}\right)$ & $-0,457$ ** & $0,407 * \star$ & $-0,317^{\star *}$ & $-0,324$ ** & $0,325^{\star \star}$ & $0,232^{*}$ & 0,238 ** & $-0,304$ ** & $0,377^{\star \star}$ & 0,122 & 0,190 * \\
\hline $\mathrm{CF}\left(\mathrm{NMP} 100^{-1} \mathrm{~mL}^{-1}\right)$ & $-0,429$ ** & $0,309 * *$ & $-0,363$ ** & $-0,171$ & 0,177 & $0,236^{*}$ & $0,443^{* *}$ & $-0,128$ & 0,333 ** & $0,207^{*}$ & $0,219^{*}$ \\
\hline CT (NMP $100^{-1} \mathrm{~mL}^{-1}$ ) & $-0,498 * *$ & $0,356^{* *}$ & $-0,421 * *$ & $-0,195^{*}$ & $0,203^{*}$ & $0,273^{* *}$ & $0,518^{* *}$ & $-0,145$ & $0,385^{\star *}$ & $0,240 *$ & $0,253^{* *}$ \\
\hline $\mathrm{pH}$ & $0,319 * *$ & $-0,189 *$ & $0,422^{* *}$ & 0,144 & 0,107 & $-0,425^{\star *}$ & $-0,551^{* *}$ & 0,026 & $-0,338$ ** & $-0,484^{\star *}$ & $-0,439 * \star$ \\
\hline $\mathrm{CE}\left(\mu \mathrm{S} \mathrm{cm}^{-1}\right)$ & $-0,536$ ** & 0,466 ** & $-0,342^{\star *}$ & $-0,374^{\star \star}$ & $0,414^{\text {** }}$ & 0,261 ** & $0,293^{* *}$ & $-0,334^{\star \star}$ & 0,431 ** & 0,142 & $0,209 *$ \\
\hline $\mathrm{Fe}\left(\mathrm{mg} \mathrm{L}^{-1}\right)$ & $-0,291^{*}$ & $0,228^{*}$ & $-0,228^{*}$ & $-0,130$ & 0,160 & 0,120 & $0,236^{*}$ & $-0,120$ & $0,216^{*}$ & 0,070 & 0,100 \\
\hline $\mathrm{OD}\left(\mathrm{mg} \mathrm{L}^{-1}\right)$ & 0,291 ** & $-0,222^{*}$ & $0,406^{* *}$ & $0,217^{*}$ & 0,088 & $-0,430$ ** & $-0,406$ ** & 0,128 & $-0,346$ ** & $-0,445^{\star *}$ & $-0,439 * *$ \\
\hline $\mathrm{Ca}\left(\mathrm{mg} \mathrm{L}^{-1}\right)$ & $-0,393$ ** & $0,393^{* *}$ & $-0,239 *$ & $-0,372^{\star \star}$ & $0,352^{\text {** }}$ & $0,216^{*}$ & 0,087 & $-0,356^{\star \star}$ & 0,347 ** & 0,083 & 0,168 \\
\hline$M g\left(m g ~ L^{-1}\right)$ & $-0,275^{* *}$ & 0,261 ** & $-0,215^{\star}$ & $-0,237^{*}$ & 0,170 & 0,190 & 0,130 & $-0,220^{*}$ & $0,255^{\text {** }}$ & 0,110 & 0,160 \\
\hline DT $\left(\mathrm{mg} \mathrm{L}^{-1}\right)$ & $-0,510$ ** & $0,502^{\star *}$ & $-0,347^{* *}$ & $-0,470 * *$ & 0,403 ** & $0,313^{\star *}$ & 0,159 & $-0,444^{\star *}$ & 0,461 ** & 0,154 & $0,258^{\star *}$ \\
\hline
\end{tabular}

Uso e Ocupação: P (pastagem), CP (culturas perenes), VV (vegetação de várzeas), M (matas densas), AU (área urbana), V (videiras), MD (matas degradadas), FRP (faixas laterais das rodovias pavimentadas), C (moradias rurais), ER (estradas rurais) e CA (culturas anuais)

Atributos Hídricos: Qesp (vazão específica), DSTesp (descarga sólida específica), T (temperatura a água), TD (turbidez), SS (sólidos suspensos), SD (sólidos dissolvidos), ST (sólidos totais), CF (coliformes fecais), CT (coliformes totais), pH (potencial hidrogeniônico), CE (condutividade elétrica), Fe (ferro total), OD (oxigênio dissolvido), Ca (cálcio), Mg (magnésio), DT (dureza total)

quase completa ausência de cobertura, baixa rugosidade superficial e maior quantidade de partículas prontamente disponíveis para o transporte, além da maior susceptibilidade do solo à erosão em sulcos.

Para a concentração de coliformes e de acordo com os resultados, as áreas habitadas, principalmente as moradias rurais, tenderam a aumentar os coliformes (Figura 3E e F); esses resultados se devem, possivelmente, aos dejetos e lixos lançados em aterros domésticos, além da criação de animais, tais como suínos aves e bovinos leiteiros, nos arreadores das moradias, sem condição de tratamento dos dejetos. O mesmo comportamento foi obtido por Gonçalves et al. (2005), ao verificarem alta contaminação biológica em locais com proximidade a um número maior de moradias e locais com muito lixo (plástico, latas e embalagens de pesticidas); já a correlação com as culturas, em especial as perenes e as perenes irrigadas, se deve, sem dúvida, à adubação com esterco em grande quantidade. De acordo com os técnicos da Coordenadoria de Assistência Técnica Integral - CATI, do município de Marinópolis, os produtores realizam adubações de até $6 \mathrm{~kg}_{\text {pé }}{ }^{-1}$ ano $^{-1}$ de esterco de galinha para a cultura da laranja e cerca de $80 \mathrm{t} \mathrm{ha}^{-1}$ ano de esterco de gado para as videiras, fato que poderia explicar tais resultados.

Com relação ao pH, verificou-se tendência de redução nos valores, provocada pelas áreas agricultadas (culturas perenes, videiras e culturas anuais), e por matas degradadas, moradias rurais e estradas rurais (Figura 4A), em função das correlações negativas observadas, novamente em função do maior escoamento superficial e, consequentemente, do maior carreamento de sólidos, dentre os quais a matéria orgânica que proporciona o aumento de sua concentração no leito do manancial; então, no processo de oxidação da matéria orgânica pelos microrganismos aeróbicos e liberação de gás carbônico em água, ocorre aumento na con- centração de ácido carbônico, resultando em redução nos valores de pH da água.

Para condutividade elétrica da água verificou-se influência das áreas habitadas (área urbana e moradias rurais), áreas agricultadas (culturas perenes e anuais) e das matas degradadas (Figura 4B), em função das correlações positivas observadas. Bertol et al. (2007), avaliando as perdas de solo, água e nutrientes das culturas na erosão entre sulcos, em solo cultivado sob diferentes preparos de solo e adubações, notaram que os valores mais elevados de condutividade elétrica da água de enxurrada foram obtidos nos tratamentos com adubação orgânica seguidos da adubação química com NPK.

Pelas correlações positivas observadas, o ferro total tem origem nas áreas ocupadas por culturas perenes, matas degradadas e moradias rurais (Figura 4C), fato que pode estar relacionado ao maior carreamento de sedimentos dessas áreas, associado ao tipo de solo da sub-bacia; resultados semelhantes foram obtidos por Primavesi et al. (2002) que, ao estudarem o efeito de atividades agrícolas sobre a qualidade da água ao longo do Córrego Canchim, em São Carlos, encontraram o valor médio mais alto de ferro total $\left(1,4 \mathrm{mg} \mathrm{L}^{-1}\right)$ em um ponto exposto às atividades agrícolas.

Com relação ao oxigênio dissolvido e em função das correlações negativas obtidas, verificou-se tendência de redução de sua concentração na água com o aumento das áreas agricultadas, matas degradadas e moradias rurais (Figura 4D). Este comportamento se deve, provavelmente, ao maior carreamento de matéria orgânica para o leito do manancial, com aumento da decomposição aeróbica e, em consequência, diminuição da concentração de oxigênio dissolvido na água. Bertol et al. (2007) encontraram valores de DQO na água de enxurrada originada de coberturas com adubação orgânica, variando de 259 a $317 \mathrm{mg} \mathrm{L}^{-1}$, fato que poderia explicar esses resultados. 
A.

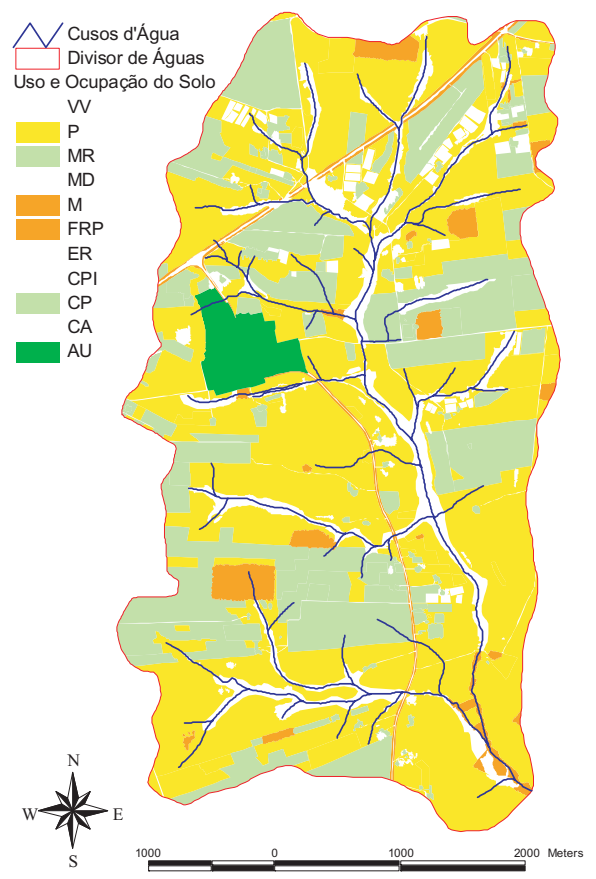

D.

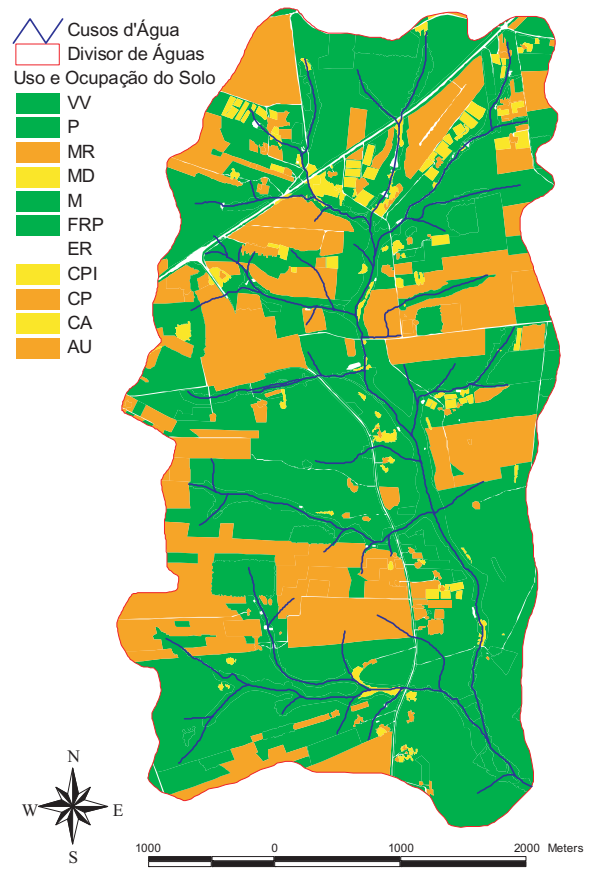

B.

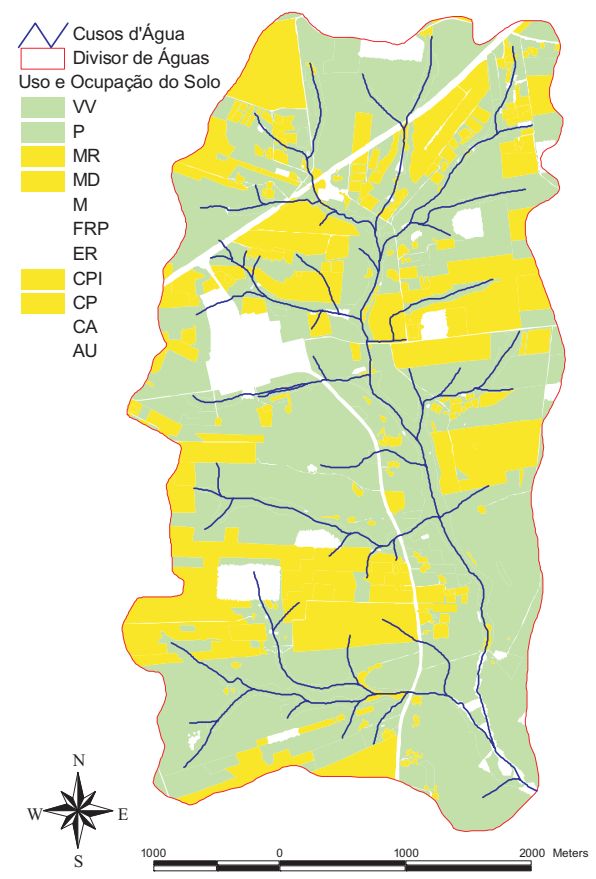

E.

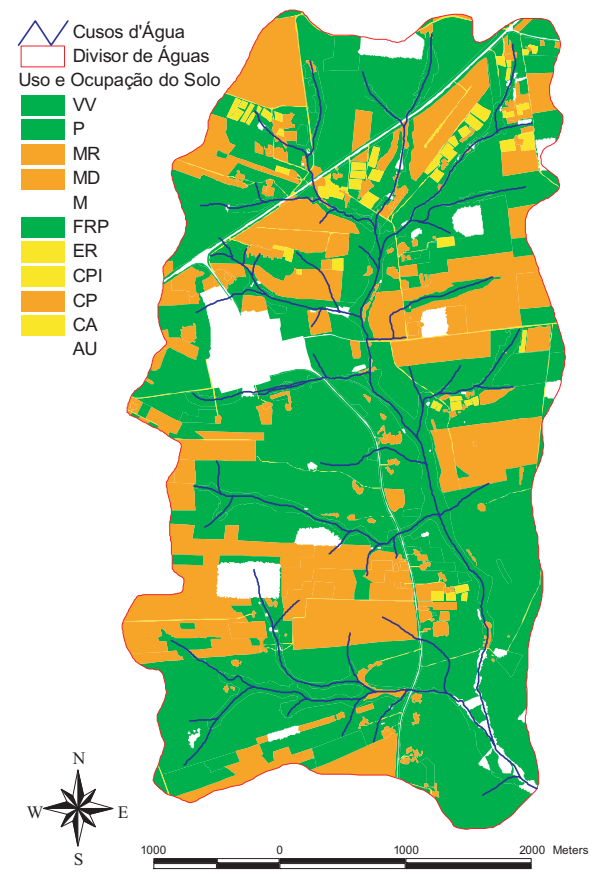

C.

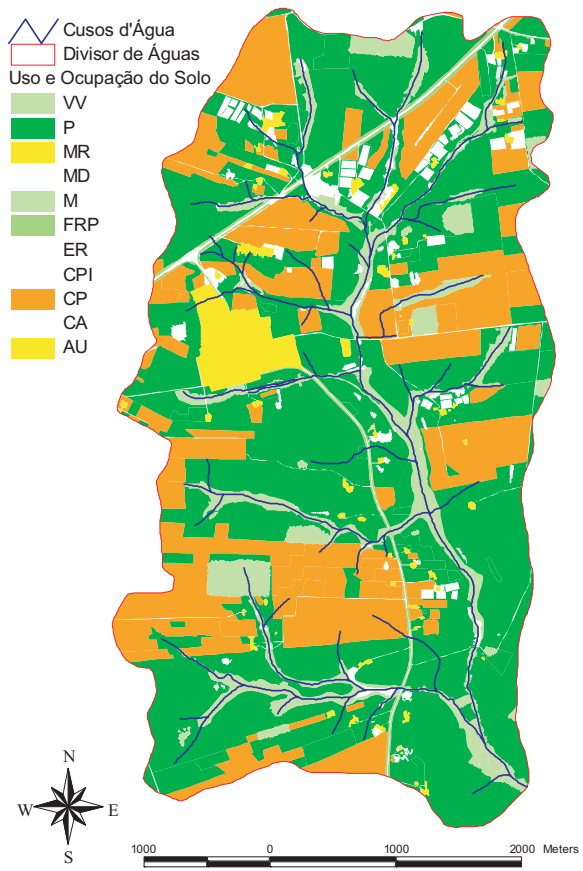

F.

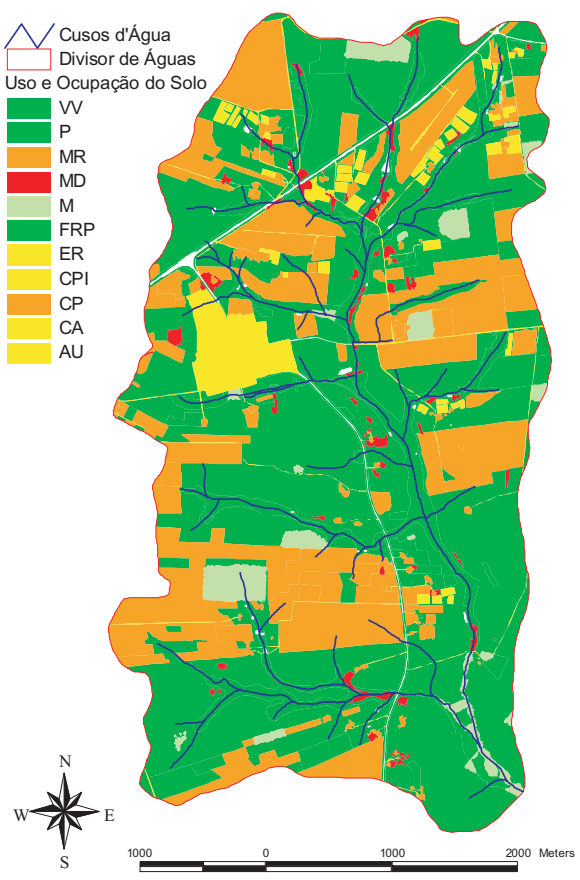

Alta

Moderada

Baixa

Nula

Figura 3. Mapa das correlações da vazão específica (A), sólidos suspensos (B), sólidos dissolvidos (C), sólidos totais (D), coliformes fecais (E) e coliformes totais (F) com o uso e ocupação dos solos

Os parâmetros cálcio, magnésio e dureza total, que indicaram comportamentos semelhantes embora com intensidades diferentes de correlação, apresentaram correlações positivas com as áreas agricultadas (culturas perenes e culturas perenes irrigadas) e habitadas (área urbana e moradias rurais) (Figuras 5A, B e C). Resultados semelhantes obtiveram Gonçalves et al. (2005), que atribuíram o aumento das concentrações de cálcio e magnésio na água, ao longo da mi- crobacia do Arroio Lino, às elevadas taxas de erosão e elevadas disponibilidades desses nutrientes no solo, fato que também pode estar ocorrendo na Sub-Bacia do Três Barras. Bertol et al. (2003), ao avaliaram as perdas de nutrientes na água da erosão hídrica constataram que o preparo convencional (aração + duas gradagens) foi o que mais contribuiu com perda de nutrientes por erosão hídrica, dentre os quais, o cálcio e o magnésio. 
A.

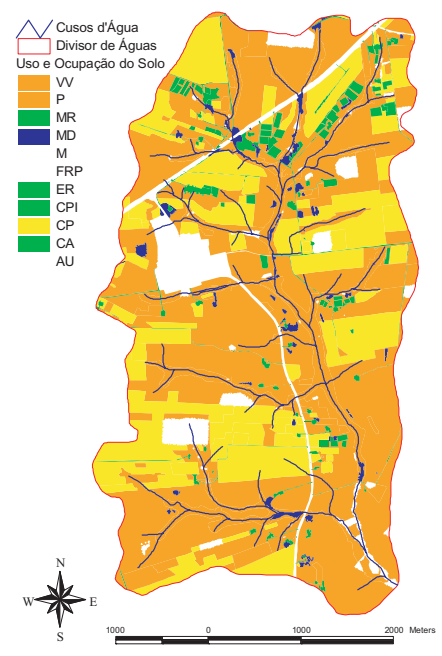

B.

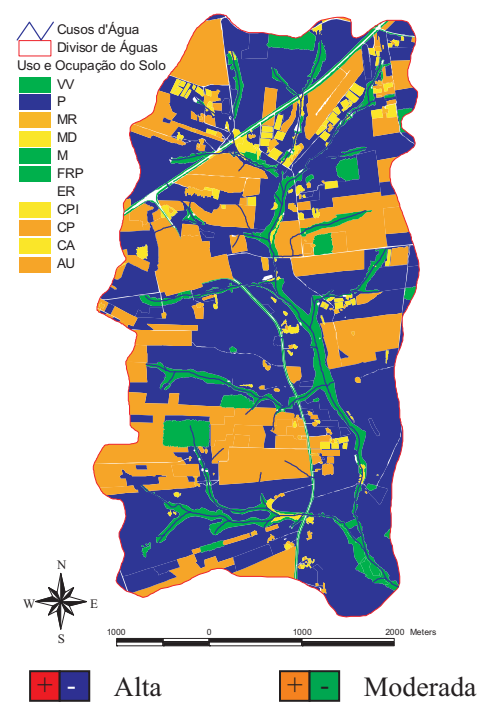

C.

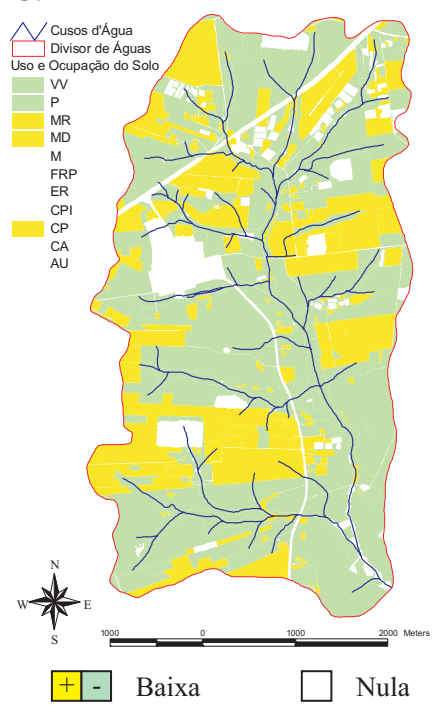

D.

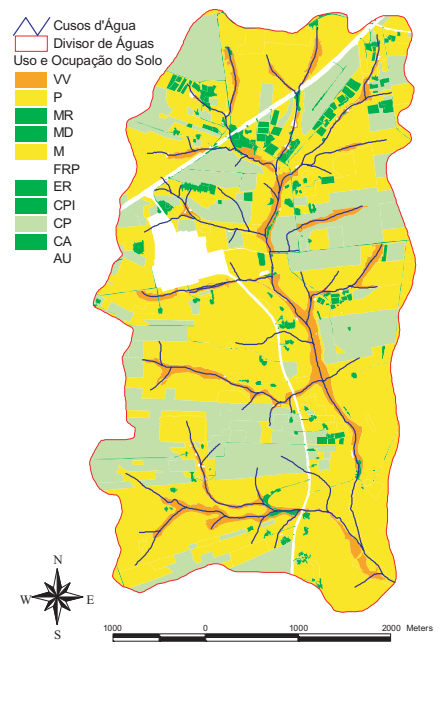

Figura 4. Mapa das correlações do pH (A), condutividade elétrica (B), ferro total (C) e oxigênio dissolvido (D) com o uso e ocupação dos solos

A.

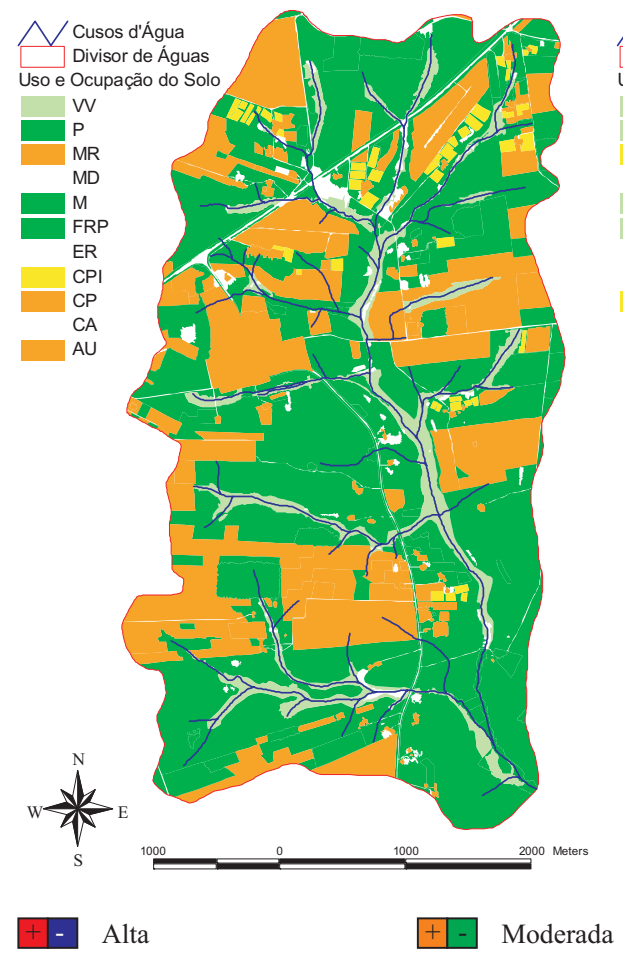

B.

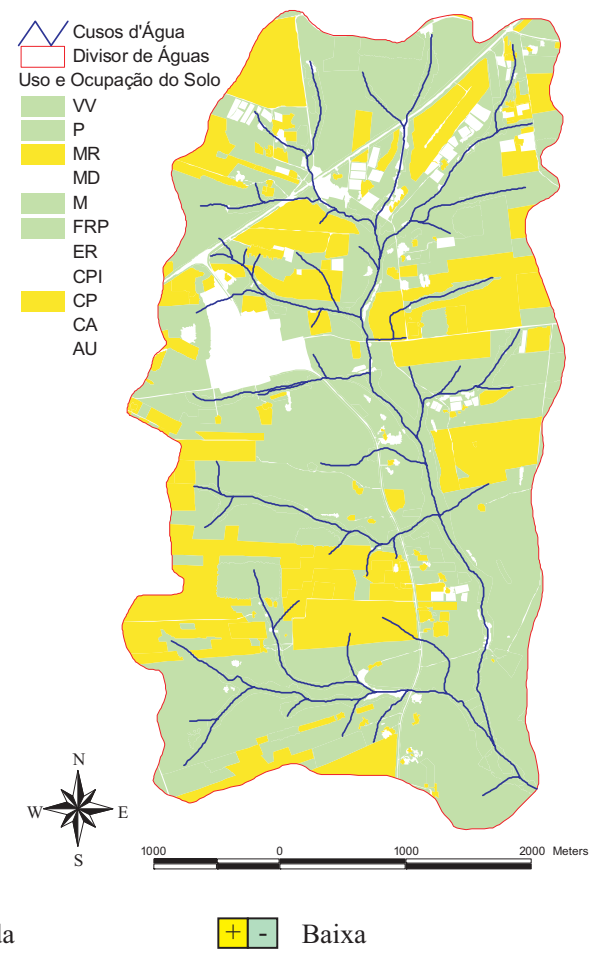

C.

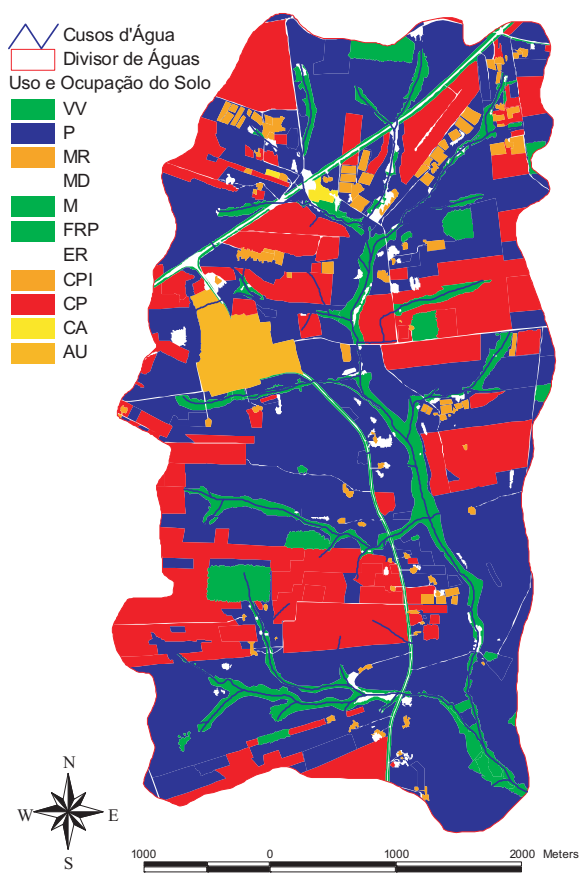

Nula

Figura 5. Mapa das correlações da concentração de cálcio (A), magnésio (B) e dureza total (C) com o uso e ocupação dos solos

Esses resultados demonstram a importância das matas na disponibilidade e qualidade da água dos mananciais, como se observa nas regressões lineares apresentadas na Tabela 8.

Da área de preservação permanente - APP, da microbacia, com o total de 251,12 ha, somente 4,4\% (10,99 ha) estão ocupadas por matas remanescentes em bom estado de conservação; se o restante da APP fosse reflorestado (área de 240,13 ha que correspondem a 13,5\% ou fração de 0,135 da área da sub-bacia) e de acordo com os resultados da Tabela 8, em longo prazo, poderia haver uma significativa
Tabela 8. Análise de regressão linear de alguns atributos hídricos com a área de matas

\begin{tabular}{lc}
\hline \multicolumn{1}{c}{ Equação de Regressão } & $\mathbf{r}$ \\
$\mathrm{Q}_{\text {esp }}=15,740 \pm 6,336+(343,999 \pm 110,953) \mathrm{M}$ & $0,311^{* *}$ \\
$\mathrm{ST}=187,679 \pm 9,577-(663,300 \pm 180,414) \mathrm{M}$ & $-0,324^{* *}$ \\
$\mathrm{CE}=287,057 \pm 14,326-(1149,489 \pm 268,370) \mathrm{M}$ & $-0,374^{\star *}$ \\
$\mathrm{DT}=142,393 \pm 3,854-(415,186 \pm 72,000) \mathrm{M}$ & $-0,470^{* *}$ \\
OD $=5,425 \pm 0,592+(26,376 \pm 11,022) \mathrm{M}$ & $0,217^{*}$ \\
\hline
\end{tabular}

OBS: Qesp (vazão específica, $\mathrm{m}^{3} \mathrm{~h}^{-1} \mathrm{~km}^{-2}$ ), ST (sólidos totais, $\mathrm{mg} \mathrm{L}^{-1}$ ), CE (condutividade elétrica, $\mu \mathrm{S} \mathrm{cm} \mathrm{cm}^{-1}$ ), OD (oxigênio dissolvido, $\mathrm{mg} \mathrm{L}^{-1}$ ), DT (dureza total, $\mathrm{mg} \mathrm{L}^{-1}$ ) e $\mathrm{M}$ (área de matas, em fração da Sub-Bacia); ** Significativo a 1\%; *Significativo a 5\% 
melhoria na disponibilidade e qualidade de água. Com a recomposição florestal a vazão específica poderia aumentar da média de 19,3 $\pm 2,1 \mathrm{~m}^{3} \mathrm{~h}^{-1} \mathrm{~km}^{-2}$ (amplitude de 17,2 a $21,4 \mathrm{~m}^{3} \mathrm{~h}^{-1} \mathrm{~km}^{-2}$ ) na Sub-Bacia 5 para uma amplitude de 40,9 a 83,6 $\mathrm{m}^{3} \mathrm{~h}^{-1} \mathrm{~km}^{-2}$ (considerando-se a equação de $\mathrm{Q}_{\text {esp }}$ da Tabela 8), o que representaria uma variação aproximada de, pelo menos, 2 a 4 vezes a mais na vazão específica.

Esses resultados são devidos, provavelmente, à capacidade da vegetação de manter a água armazenada na sub-bacia, o que permite inferir que a maior contribuição seja para o escoamento de base, já que diversos autores, por meio de estudos em bacias experimentais, verificaram aumento da vazão média com a retirada da floresta ou vegetação natural (Tucci, 2003).

Para a qualidade de água e se comparando a amplitude obtida pelas regressões da Tabela 8 em relação à média dos atributos de qualidade da água na Sub-Bacia 5, alguns resultados seriam: redução de 14,1 a $60,4 \%$ na concentração de sólidos totais (comparando-se com a média de $157,9 \pm 4,1 \mathrm{mg} \mathrm{L}^{-1}$ ); redução de 8,7 a $63,5 \%$ na condutividade elétrica da água (comparando-se com a média de $211,4 \pm 11,5 \mu \Sigma \mathrm{cm}^{-1}$ ), redução de 16.4 a 43,9\% na dureza total (comparando-se com a média de 124,6 \pm 5,1 $\mathrm{mg} \mathrm{L}^{-1}$ ) e aumento de até $53,7 \%$ na concentração de oxigênio dissolvido (comparando-se com a média de 8,1 \pm 0,9 $\mathrm{mg} \mathrm{L}^{-1}$ ).

De acordo com os resultados apresentados, as áreas ocupadas por matas favorecem o aumento da vazão específica em virtude da maior cobertura, estabilidade e infiltração de água no solo promoverem redução da intensidade do escoamento superficial contribuindo também para a melhoria da qualidade da água. De maneira geral, as áreas habitadas (área urbana e moradias rurais), agricultadas (culturas perenes, perenes irrigadas e anuais) e as matas degradadas, contribuem para a redução da vazão específica e da qualidade de água em função da alteração na intensidade do escoamento superficial.

De acordo com os resultados obtidos por Machado et al. (2003), ao simularem cenários alternativos de uso e ocupação da terra na microbacia hidrográfica do Ribeirão dos Marins, há necessidade de se tratar a paisagem em bacias hidrográficas, de forma global, identificando-se as “áreas ambientalmente sensíveis”, em que são necessárias práticas de controle dos processos erosivos ou mudanças de uso da terra e não somente a proteção dispensada aos cursos d'água por meio da mata ciliar.

Com os resultados obtidos para a Sub-Bacia do Córrego Três Barras verifica-se, como prioridade, a recomposição das áreas de preservação permanente; no entanto, nas áreas agricultadas também devem ser executadas melhorias na conservação do solo pela adoção das práticas conservacionistas, tais como terraceamento e manutenção de cobertura permanente de vegetação nas entre linhas de plantio das culturas perenes.

\section{CONCLUSÕES}

1. As áreas ocupadas por matas e pastagens (em menor intensidade) favoreceram o aumento da vazão específica e a melhoria de alguns atributos de qualidade de água na SubBacia 5 (Córrego Três Barras).

2. As áreas habitadas, agricultadas e as matas degradadas reduziram, de maneira geral, a vazão específica e a qualidade de água da Sub-Bacia 5.

\section{AGRADECIMENTOS}

Os autores agradecem à FAPESP e ao FEHIDRO, por meio do $\mathrm{CBH}-\mathrm{SJD}$, pelo apoio financeiro, e aos produtores rurais e técnicos da CATI - Casa da Agricultura de Marinópolis, SP, pelo apoio aos trabalhos realizados.

\section{LITERATURA CITADA}

Andrade, E. M. de; Araújo, L. de F. P.; Rosa; M. F.; Gomes, R. B.; Lobato, F. A. de O. Seleção dos indicadores da qualidade das águas superficiais pelo emprego da análise multivariada. Engenharia Agrícola, v.27, n.3, p.683-690, 2007.

Bertol, I.; Guadagnin, J. C.; Cassol, P. C.; Amaral, A. J.; Barbosa, F. T. Perdas de fósforo e potássio por erosão hídrica em um Inceptisol sob chuva natural. Revista Brasileira de Ciência do Solo, v.28, p.485-494, 2004.

Bertol, I.; Mello, E. L.; Guadagnin, J. C.; Zaparolli, A. L. V.; Carrafa, M. R. Nutrient losses by water erosion. Scientia Agricola, v.60, n.3, p.581-586, 2003.

Bertol, O. J.; Rizzi, N. E.; Bertol, I.; Roloff, G. Perdas de solo e água e qualidade do escoamento superficial associadas à erosão entre sulcos em área cultivada sob semeadura direta e submetida às adubações mineral e orgânica. Revista Brasileira de Ciência do Solo, v.31, p:781-792, 2007.

Carvalho, N. O. Hidrossedimentologia prática. Rio de Janeiro: CPRM, 1994. 372p.

CBH-SJD - Comitê da Bacia do São José dos Dourados. Diagnóstico da situação atual dos recursos hídricos e estabelecimento de diretrizes técnicas para a elaboração do Plano da Bacia Hidrográfica do São José dos Dourados. São Paulo: CBH-SJD, 2000. 119p.

Donadio, N. M. M.; Galbiatti, J. A.; Paula, R. C. de. Qualidade da água de nascentes com diferentes usos do solo na bacia hidrográfica do Córrego Rico, São Paulo, Brasil. Engenharia Agrícola, v.25, n.1, p.115-125, 2005.

Gomes, N. M.; Faria, M. A. de; Silva, A. M. da; Mello, C. R. de; Viola, M. R. Variabilidade espacial de atributos físicos do solo associados ao uso e ocupação da paisagem. Revista Brasileira de Engenharia Agrícola e Ambiental, v.11, n.4, p.427-435, 2007.

Gonçalves, C. S.; Rheinheimer, D. dos S.; Pellegrini, J. B. R.; Kirst, S. L. Qualidade da água numa microbacia hidrográfica de cabeceira situada em região produtora de fumo. Revista Brasileira de Engenharia Agrícola e Ambiental, v.9, n.3, p.391-399, 2005.

Hernandez, F. B. T.; Souza, S. A. V. de; Zocoler, J. A. Simulação e efeito de veranicos em culturas desenvolvidas na região de Palmeira d'Oeste, estado de São Paulo. Engenharia Agrícola, v.23, n.1, p.21-30, 2003.

R. Bras. Eng. Agríc. Ambiental, v.14, n.1, p.55-64, 2010. 
Hopkins, W.G. A new view of statistics. Internet Society for Sport Science. http://www.sportsci.org/resource/stats/. 23 Jan. 2008. Machado, R. E.; Vettorazi, C. A.; Xavier, A. C. Simulação de cenários alternativos de uso da terra em uma microbacia utilizando técnicas de modelagem e geoprocessamento. Revista Brasileira de Ciência do Solo, v.27, p.727-733, 2003.

Oliveira, J. B.; Camargo, M. N.; Rossi, M.; Calderano Filho, B. Mapa pedológico do Estado de São Paulo: Legenda expandida. Campinas: Instituto Agronômico/Embrapa Solos. 1999. 64p.

Primavesi, O.; Freitas, A. R. de; Primavesi, A. C.; Oliveira. H. T. Water quality of the canchim's creek watershed in São Carlos, SP, Brazil, occupied by beef and dairy cattle activities. Brazilian Archives of Biology and Technology, v.45, n.2, p.209-217, 2002.

Rolim, G. de S.; Camargo, M. B. P. de; Lania, D. G.; Moraes, J. F. L. de. Classificação climática de Köppen e de Thornthwaite e sua aplicabilidade na determinação de zonas agroclimáticas para 0 Estado de São Paulo. Bragantia, v.66, p.711-720, 2007.
São Paulo. Secretaria do Meio Ambiente. Relatório de qualidade ambiental do Estado de São Paulo 2006. São Paulo: Secretaria do Meio Ambiente, 2006. 498p.

Silva, D. D.; Pruski, F. F.; Schaefer, C. E. G. R.; Amorim, R. S. S.; Paiva, K. W. N. Efeito da cobertura nas perdas de solo em um Argissolo Vermelho-Amarelo utilizando simulador de chuva. Engenharia Agrícola, v.25, n.2, p.409-419, 2005.

Toledo, L. G. de; Niconella, G. Índice de qualidade de água em microbacia sob uso agrícola e urbano. Scientia Agricola, v.59, n.1, p.181-186, 2002.

Tucci, C. E. M. Vazões médias. In: Paiva, J. B. D. de; Paiva, E. M. C. D. de. Hidrologia aplicada à gestão de pequenas bacias hidrográficas. Porto Alegre: ABRH, 2003. cap.1, p.113-124.

Zigomar, M. de S.; Alves, M. C. Movimento de água e resistência à penetração em um Latossolo Vermelho distrófico de cerrado, sob diferentes usos e manejos. Revista Brasileira de Engenharia Agrícola e Ambiental, v.7, n.1, p.18-23, 2003. 